\title{
Population resilience of the Mediterranean monk seal Monachus monachus at Cabo Blanco peninsula
}

\author{
M. Martínez-Jauregui ${ }^{1, *}$, G. Tavecchia ${ }^{2}$, M. A. Cedenilla ${ }^{3}$, T. Coulson ${ }^{4}$, \\ P. Fernández de Larrinoa ${ }^{3}$, M. Muñoz ${ }^{3}$, L. M. González ${ }^{5}$ \\ ${ }^{1}$ CIFOR-INIA, Carretera de La Coruña, Km 7.5, 28040 Madrid, Spain \\ ${ }^{2}$ Institut Mediterrani d'Estudis Avançats (IMEDEA), CSIC-UIB, Miquel Marques 21, Esporles, Mallorca 07190, Spain \\ ${ }^{3}$ Fundación CBD-Habitat, c/Gustavo Fernández Balbuena 2, 28002 Madrid, Spain \\ ${ }^{4}$ Division of Biology, Imperial College London, Silwood Park, Ascot, Berkshire SL5 7PY, UK \\ ${ }^{5}$ Ministerio de Medio Ambiente y Medio Rural y Marino, c/ Ríos Rosas 24, 28003 Madrid, Spain
}

\begin{abstract}
Environmental and demographic stochasticity alone can push small populations to extinction. However, some small populations can persist for a long time at a low density, maintaining potential for rapid growth. We investigated the demographic mechanisms underlying the response of the population of the Mediterranean monk seal Monachus monachus on the Cabo Blanco peninsula (Mauritania/Morocco). The population was dramatically reduced after a demographic crash in 1997, which was initially thought to have pushed the population toward extinction. Census data, individual-based data on presence-absence and breeding state data were obtained by direct observation, by photo-identification and through the analysis of video images at the only known breeding sites for the species. We found that the monk seal population at Cabo Blanco is recovering, with means of $31(24.8,36.8)$ sub-adults, $46(42.3,49.7)$ adult females and 39 $(29.1,48.4)$ adult males using the 2 breeding sites in 2007 . The population structure is similar to proportions prior to the mass mortality event. Annual survival probabilities for sub-adults, adult females and adult males were 0.81 (0.676 to 0.904$), 0.99$ (0.926 to 0.998 ) and 0.87 (0.81 to 0.94 ), respectively. At present, juvenile survival is unknown, but the high survival of females and the high breeding potential are likely to be responsible for the population recovery.
\end{abstract}

KEY WORDS: Small population $\cdot$ Capture-recapture $\cdot$ Catastrophic event $\cdot$ Demography $\cdot$ Photoidentifications $\cdot$ Marine mammals

\section{INTRODUCTION}

Small populations are at greater risk of extinction than large ones as a result of environmental variation or demographic stochasticity and processes, such as the Allee effect (Lande 1993, Mangel \& Tier 1994, Courchamp et al. 1999, Coulson et al. 2001, Gerber \& Hilborn 2001, Berec et al. 2007, Good et al. 2008, Melbourne \& Hastings 2008). These general conclusions raise concerns for the conservation of small populations. However, small populations do not necessarily become extinct. In some cases, they can per- sist for long periods of time at a low density while maintaining a potential for fast growth when conditions improve. The potential for fast growth at low density is evident, for example, when unoccupied suitable habitats become colonised by a small number of individuals. The initial colonisation phase is typically followed by an exponential increase despite the small number of founders (Oro \& Ruxton 2001). Similarly, small populations might recover from a catastrophic event and continue to grow faster than before the catastrophe (Martinez-Abrain et al. 2012). The potential for fast growth after a catastrophic 
event, and the mechanisms that permit a population to increase in size towards carrying capacity, are poorly understood (Gerber \& Hilborn 2001, González et al. 2002). Study of the resilience of small populations after a catastrophic event helps to identify the drivers and synergistic processes that explain and predict recoveries of populations of endangered species, and thus provides important information for the conservation of such populations.

The Mediterranean monk seal is one of the largest of the phocid species and, jointly with Hawaiian monk seals Monachus schauinslandi, is found at the lowest latitudes reported for this taxon. Since 1996, the species has been considered critically endangered, and is listed among the most endangered mammals on earth (IUCN 2010). Once distributed throughout the whole Mediterranean basin, among the eastern Atlantic islands (from the Azores to Cabo Verde) and along the north-western coast of Africa, the Mediterranean monk seal is now confined to 3 isolated populations. One is located in the north-eastern Mediterranean along the Greek and Turkish coasts and the other 2 are in the Atlantic Ocean. Individuals of the Atlantic populations breed regularly only along the west coast of Cabo Blanco (Mauritania/Morocco) and in the Madeira archipelago (Desertas Island). The Cabo Blanco population is the largest known breeding colony of the Mediterranean monk seal (González et al. 1997, González 2006). In 1997, however, Forcada et al. (1999) documented a two-third reduction in the size of Cabo Blanco population due to a massive increase in mortality. This mortality was followed by a shift of the population structure, since adults were the most affected, and therefore the proportion of juveniles increased. Various causes of the sudden increase in mortality have been proposed (Harwood 1998). The most likely explanation is that a toxic algal bloom killed large numbers of adult seals (Reyero et al. 1999). After 1997, when the population reached its minimum size, the predicted outcome was extinction, due to the skewed age-structure and depressed rates of productivity (Forcada et al. 1999, Pastor et al. 2004). Nevertheless, field observations suggested a slow recovery of seal numbers. Here we investigated the demographic mechanisms underlying the response of the Cabo Blanco population of the Mediterranean monk seal Monachus monachus after the 1997 demographic crash. We used a range of data types to (1) describe the population trend since the population crash, (2) estimate variation in the demographic parameters to help identify management strategies and (3) understand how extinction was avoided.

\section{MATERIALS AND METHODS}

\section{Population counts and individual life-history data}

We considered a range of available data collected from 2 neighbouring breeding caves of Monachus monachus (Table 1), where most of the births take place along the Atlantic coast of Africa (González et al. 2002). We used count data and presence-absence data from different sources to construct individual capture histories.

An initial index of population size was obtained by counting seals at the entrance to the caves. From 2004 to 2007 the number of seals and their morphological states were recorded by the same observer and summarised into the maximum number of simultaneous counts and sex- and age-structure. On average, data were collected for $3.5 \mathrm{~d} \mathrm{mo}^{-1}$ (there were only 3 months with a single sample day). Following

Table 1. Monachus monachus. Details of the available data collected from 2 neighbouring breeding caves on Cap Blanc peninsula (age/sex classes, following Samaranch \& González (2000), are-P: pups; Y: young individuals; SA: sub-adults; AF: adult females; AM: adult males). Each sampling day is defined as 2 consecutive field days: 1 in each cave. Catalogue: see 'Materials and methods: Population counts and individual life-history data'

\begin{tabular}{|c|c|c|c|}
\hline $\begin{array}{l}\text { Data collection } \\
\text { method }\end{array}$ & $\begin{array}{l}\text { Age/sex classes } \\
\text { considered }\end{array}$ & $\begin{array}{l}\text { Sample freq./no. of } \\
\text { sampling di date }\end{array}$ & $\begin{array}{l}\text { No. of seals. in } \\
\text { the catalogue }\end{array}$ \\
\hline $\begin{array}{l}\text { Counting seals at the } \\
\text { entrance of the caves }\end{array}$ & $\mathrm{P}, \mathrm{Y}, \mathrm{SA}, \mathrm{AF}, \mathrm{AM}$ & $\begin{array}{c}\text { Every month } \\
\text { (mean: } 3.5 \text { samples d }^{-1} \mathrm{mo}^{-1} \text { ); } 2004-2007\end{array}$ & \\
\hline $\begin{array}{l}\text { Photo-identification of seals } \\
\text { entering or leaving caves }\end{array}$ & $\mathrm{SA}, \mathrm{AF}$ & $\begin{array}{l}13 d_{;} \text {Jun-Aug } 2003 \\
12 d_{;} \text {May-Jun } 2005 \\
15 d_{;} \text {Sep-Oct } 2006 \\
15 d_{;} \text {Sep-Oct } 2007\end{array}$ & $97 \mathrm{SA}$ and $\mathrm{AF}$ \\
\hline $\begin{array}{l}\text { Photo-identification of seals by video } \\
\text { images taken inside largest cave }\end{array}$ & $\mathrm{AM}, \mathrm{P}$ & Every day; 2003-2007 & $57 \mathrm{AM}$ \\
\hline
\end{tabular}


Samaranch \& González (2000), we sorted individuals into 5 morphological categories. These categories were based on age- and sex-classes, but included some error as the category could not always be unambiguously defined. The 5 categories were: pups ( 0 to 2 mo old, denoted ' $\mathrm{P}^{\prime}$ ), young (aged between approximately $2 \mathrm{mo}$ and $2.5 \mathrm{yr}$ ' 'Y'), medium-sized grey-pelage seals (sub-adults aged approximately 2.5 to $4 \mathrm{yr}$ ' 'SA'), large grey-pelage seals (mostly adult females, aged approximately $>4 \mathrm{yr}$ old, 'AF') and large black-pelage males (aged approximately $>4 \mathrm{yr}$, 'AM'). Because sexual size dimorphism in monk seals is only evident after sexual maturity, the first 3 categories ( $\mathrm{P}, \mathrm{Y}$ and $\mathrm{SA}$ ) included males and females.

In addition to the count data, individual-based data on presence-absence and breeding state were obtained via 2 different resighting processes: (1) photoidentification of animals from pictures taken of individuals entering or leaving both caves. Pictures were taken in at least 12 consecutive sampling days in 4 different years from the top of the cliff above the cave entrances and (2) the analysis of video images recorded by permanent cameras placed inside the largest cave where nearly all births occurred. Two different resighting processes were used because of limitations resulting from the differences in behaviour of seals according to their age and sex. Identification from pictures taken from the cliff top was only possible for sub-adults and adult females (the 'SA' and 'AF' categories). Adult males were not identified from these pictures, as they typically have distinguishing marks on the ventral part of their body that were not visible when they entered the cave. Presence-absence data of adult males were taken from the analysis of video-images recorded by a camera placed inside the largest cave.

All seals were individually recognized by natural marks including scars and fur patterns (Forcada \& Aguilar 2000). Photo-identification avoided the stress associated with capture and the use of potentially harmful methods of marking. The individual morphological state of each recognised individual was recorded as above (Samaranch \& González 2000). There was some uncertainty in the morphological classification of individuals, and 24 out of 111 photoidentified individuals were allocated to 2 different categories. When this happened, we retained for each individual the category with the largest number of allocations.

SA and AF individuals were identified by comparing photographs with an annually updated catalogue (97 SA and AF individuals in the catalogue). Samples for SA and AF were available in June to August 2003 (13 sampling days), in May to June 2005 (12 sampling days), in September to October 2006 (15 sampling days) and in September to October 2007 (15 sampling days). Each sampling day is defined as 2 consecutive field days: $1 \mathrm{~d}$ of observing from the cliffs above each cave.

Adult males were identified by video-images, which were reviewed almost every day from 2003 until 2007, and then compared with a constantly updated catalogue of photographs of 57 different adult males made from previous pictures, drawings, or video-images. To avoid double counting, the images used in the analysis were filtered, and we only analysed those AM-images which correspond to the left side of individuals.

Young individuals had only a few marks on their body and could not be properly identified (Forcada \& Aguilar 2000). Finally, all pups that survived at least a day were identified in each cave by direct observation and by using video-images recorded by the same camera used to identify males placed in the largest cave. The number of identified pups was taken as a measure of productivity.

\section{Presence-absence data analysis}

Data on the presence-absence of seals of SA, AF and AM categories were analysed using a generalized Jolly-Seber model and POPAN parameterization (Schwarz \& Arnason 1996). In POPAN formulation, a super-population is defined, $N$, consisting of all subadult and adult seals that could have been incorporated into the population. We estimated the following parameters - phi(i): the probability of survival between 2 consecutive sampling occasions $i$ and $i+1$; $p(i)$ : the probability of capture at occasion $i_{i} \operatorname{pent}(i)$ : the probability that an animal from the super-population enters the population between 2 consecutive occasions; and N: super-population size. The population size at time $i, \mathrm{~N}$-hat(i), and the net recruitment, B-hat(i) are estimated as derived parameters (Schwarz \& Arnason 1996). Derived estimates of the population size are found iteratively so that for example, $\mathrm{N}$-hat(1) = N $\times$ pent(0), N-hat(2) = N-hat(1) $\times \operatorname{phi(1)+}$ $N \times$ pent(1), and their standard errors are calculated using the Delta method (Schwarz \& Arnason 1996).

Presence-absence data for both sub-adults and female adults, SA and AF, and adult males, AM, were analysed separately due to the different nature of the data and the different behaviour of individuals (for a similar case see Catchpole et al. 2000). Young indi- 
viduals were not considered in the analysis since they are part of the non-distinctive part of the population (Forcada et al. 1999, Forcada \& Aguilar 2000). Note that we had to assume that individuals did not change category over the period of the study. This is a limitation of our analysis as this assumption clearly does not hold for young and sub-adult seals, but, considering the relatively short period of the study, we believe we introduced only small biases to the overall results (see 'Discussion' for further considerations).

For sub-adults and adult females (SA and AF) we analysed the yearly live encounters. We considered that survival (phi), capture probability (p), and probability of an animal from the super-population entering the population between 2 consecutive (pent) sampling occasions could vary between occasions (noted 'year' in model notation) and morphological classes (noted ' $h$ '), and that super-population size (N) could also vary between morphological classes. We thus began by fitting a general model, noted $\{$ phi $($ year $\times h)$ p $($ year $\times h)$ pent $($ year $\times h) N(h)\}$, which assumed an effect of year, different parameters for each morphological group in all parameters (with the exception of $\mathrm{N}$ ) and their statistical interaction (noted ' $x$ '). For adult males (AM) we analysed data in monthly intervals, beginning with the general model \{phi(month) $\mathrm{p}$ (month) pent(month) $\mathrm{N}\}$ assuming all parameters to be month dependent (with the exception of N). Note that this general model had some convergence problems likely due to survival probability being too close to unity for the short time interval and we thus used a sine link rather than the usual logistic link.

Full models were fitted using the program MARK (White \& Burnham 1999), following the procedure described in Cooch \& White (2007). Models were simplified and compared using AICc (corrected Akaike information criterion), calculated as the model deviance plus twice the number of estimable parameters in the model, with a correction for finite sample sizes (Burnham \& Anderson 2000). The model with the lowest AICc value was considered the best compromise between the variance explained and the model complexity. Models with similar AICc values were considered equally good. To be sure that treating the morphological classes as static did not change the estimated number of sub-adult and female adult seals, we repeated the analysis for these classes by merging them into a single category. Two models differing by $>2$ points in AICc values were arbitrarily considered as different, but to account for model uncertainty, we used model averaging to obtain an averaged estimate of super-population size based on model weight (Burnham \& Anderson 2000). Finally, the goodness of fit of the most general model for survival and recapture was determined using the UCARE software (Choquet et al. 2009).

\section{A measure of resighting effort}

To reduce the number of parameters and increase the statistical power in characterising population trends since the population crash, we investigated whether resighting probabilities depended on the resighting effort. As SA- and AF-images were taken in yearly sessions from the top of the cliff, sampling effort used was constant for these categories. However, we defined 3 variables that describe the possible effort used to identified adult males (AM); these resulted from the analysis of recorded video-images: (1) the sum of the number of hours of recording every month (denoted ' $\mathrm{H}^{\prime}$ ); (2) the number of different pups identified in the cave every month (denoted 'NP'), which was the main objective of the video-camera installation; and (3) a categorical variable that describes the presence $($ value $=1)$ or absence (value $=$ 0 ) of pups in the cave (denoted ' $\mathrm{P}$ '). We considered these variables and their possible interactions as predictors of the probability of recapture in the POPAN formulation used for adult males. However, NP and P were never fitted in the same model to avoid problems of collinearity.

\section{RESULTS}

The maximum number of simultaneous counts of Monachus monachus in both caves for every morphological class varied markedly over the period considered (Fig. 1). Data show that the average population composition for the period 2004 to 2007 (n = $48 \mathrm{mo})$ was $13.2 \pm 8.4 \%$ (mean $\pm \mathrm{SE})$ pups, $13.0 \pm$ $3.7 \%$ young individuals, $24.0 \pm 6.1 \%$ sub-adults, 27.2 $\pm 5.9 \%$ adult females, $18.5 \pm 7.4 \%$ adult males and $4.2 \pm 3.9 \%$ individuals with an unknown morphological type.

For sub-adult and adult female seals the most parsimonious model \{phi(h) p(.) pent(h) N(h)\}) assumed a constant value of survival over the years, but a different value for each category considered (Appendix 1). Annual survival parameters with 95\% confidence limits were $0.81(0.676,0.904)$ and $0.99(0.926,0.998)$, for $\mathrm{SA}$ and $\mathrm{AF}$, respectively. The probability of recapture was constant for both categories and over time, $0.90(0.827,0.947)$. The probability pent was constant 


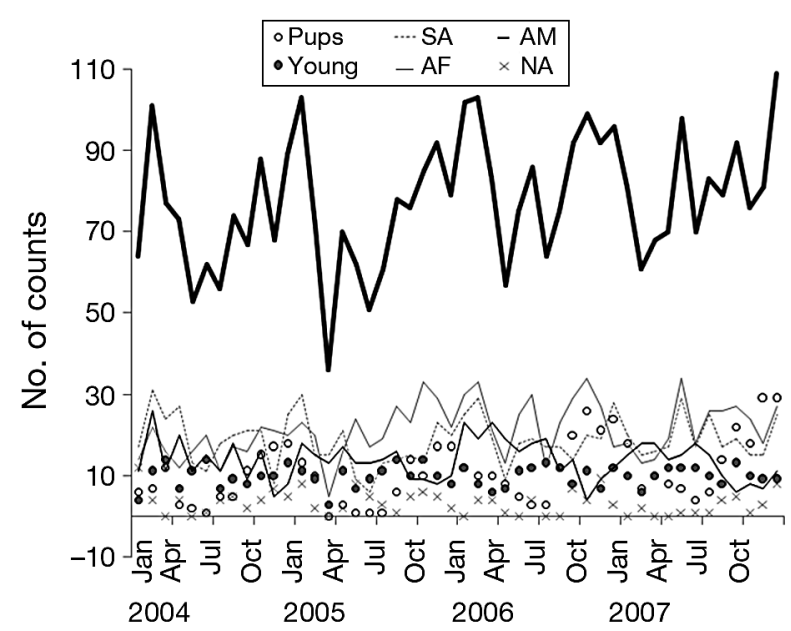

Fig. 1. Monachus monachus. Maximum number of simultaneous counts in both caves for every morphological class every month sampled. SA: sub-adult; AF: adult female; AM: adult male; NA: seals with an unknown morphological type; thick solid line: total number of seals sampled

in time, but variable between classes from 0.26 $(0.221,0.309)$ for SA to $0.09(0.047,0.155)$ for AF. Similarly, the estimated super-population size varied between classes. We estimated a super-population size of $41.4(40.3,48.1)$ sub-adult seals and 48.0 (48.0, 51.4) adult female seals (Table 2). The averaged values for these estimates were 41.2 ( $\mathrm{SE}=1.37)$ and 48.0 $(\mathrm{SE}=0.17)$. Also annual size of the population that used the caves in the period sampled (derived parameters from the model fitted) ranged from 9 to 31 sub-adults and from 35 to 46 adult females (Table 2, Fig. 2). We did a 'global test' to measure the goodness of fit of the sub-adult and adult female models, but we had insufficient data to run it properly. However, it is important to note that we conducted additional analyses (not shown) using 'robust design' with the Huggins approach (following Cooch \& White 2007) and considering a unique morphological class, and results were consistent with the ones presented here (the best model fitted considered random movement, a survival variable with time, constant capture probability and size estimates for SA and AF in a joint category. Size estimates were 44 in 2003, 60 in 2005, 68 in 2006 and 79 in 2007).

For adult males (AM), results from the goodness of fit test indicate a good fit for the general model fitted with the adult male data (Chi-squared $=94.57$, $\mathrm{df}=$ 125, $\mathrm{p}=0.98)$. However, we found some heterogeneity in the recapture probability across adult males, suggesting that some individuals might use caves more often than others (some trap dependence: $Z$-test for trap dependence $=-4.1695, \mathrm{p}=<0.01$ ). Due to the non-significance of the global test and the relatively low number of individuals in the data base, we did not consider this trap dependence in the analysis. We began by simplifying the monthly variation of parameters as a function of the year or as assuming a constant value. The retained model was one assuming constant survival, monthly variable capture and yearly variation in cave use (\{phi(.) p(month)

Table 2. Monachus monachus. Population size and 95\% confidence intervals of the seal colony on Cap Blanc peninsula compared with estimates published by Forcada et al. (1999). SA: sub-adults; AF: adult females; AM: adult males. Estimated sizeCorrected: includes juveniles and distinctiveness; Distinctive: proportion of seals with reliable marks in the colony

\begin{tabular}{|c|c|c|c|c|c|}
\hline \multirow{2}{*}{$\begin{array}{l}\text { Sampling } \\
\text { period }\end{array}$} & \multirow[t]{2}{*}{ SA } & \multirow[t]{2}{*}{$\mathrm{AF}$} & \multirow[t]{2}{*}{ AM } & \multicolumn{2}{|c|}{ Estimated size } \\
\hline & & & & Corrected & Distinctive \\
\hline \multicolumn{6}{|c|}{ Annual estimated size of super-population calculated by Forcada et al. (1999) } \\
\hline 1993 May-Jun & & & & $322(149,783)$ & $196(91.0,477.6)$ \\
\hline 1994 Mar-May & & & & $311(240,426)$ & $211(163,290.0)$ \\
\hline 1995 Apr-Jun & & & & $316(263,394)$ & $240(200.0,299.4)$ \\
\hline 1996 Apr-Jul & & & & $317(237,447)$ & $247(185.0,349.0)$ \\
\hline 1997 Jul-Oct & & & & $109(88,145)$ & $63(51.0,84.1)$ \\
\hline 1998 May-Aug & & & & $103(77,148)$ & $60(44.7,85.8)$ \\
\hline \multicolumn{6}{|c|}{ Annual estimated size of distinctive proportion of colony that used caves in period sampled } \\
\hline 2003 Jun-Aug & $9(3.3,14.3)$ & $35(27.9,42.9)$ & $31(23.7,39.5)^{\mathrm{a}}$ & & $75(54.9,96.7)$ \\
\hline 2005 May-Jun & $17(14.0,19.4)$ & $39(33.4,43.9)$ & $30(23.8,38.0)^{\mathrm{a}}$ & & $86(71.2,101.3)$ \\
\hline 2006 Sep-Oct & $24(20.9,28.1)$ & $42(38.7,46.0)$ & $31(23.0,39.0)^{\mathrm{a}}$ & & $97(82.6,113.1)$ \\
\hline $2007 \mathrm{Sep}-\mathrm{Oct}$ & $31(24.8,36.8)$ & $46(42.3,49.7)$ & $39(29.1,48.4)^{\mathrm{a}}$ & & $116(96.2,134.9)$ \\
\hline \multicolumn{6}{|c|}{ Multi-year super-population estimated size } \\
\hline $\begin{array}{l}2004-2007 \text { for } \mathrm{SA}, \mathrm{AF}_{i} \\
2000-2007 \text { for } \mathrm{AM}\end{array}$ & $41(40,48)$ & $48(48,51)$ & $62(53,70)$ & & \\
\hline
\end{tabular}




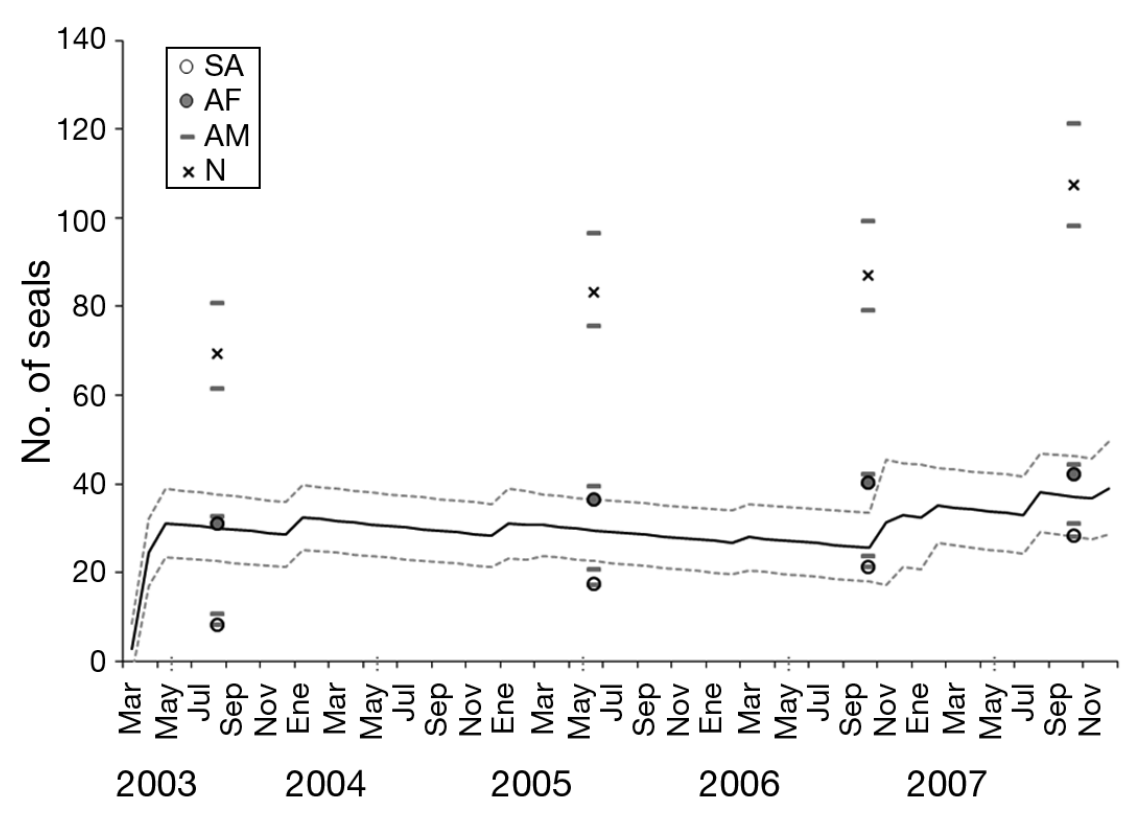

Fig. 2. Monachus monachus. Numbers of sub-adult (SA), adult female (AF) and adult male (AM) seals and estimated population size of the distinctive proportion of the colony $(\mathrm{N})$ that used the monitored caves during the period of the study; $95 \%$ confidence intervals of the estimates are also included

pent(year) $\mathrm{N}\}$; Appendix 1). As expected the monthly survival of adult males was very high, 0.99 (0.981, 0.993). This value predicts an average annual survival of $0.87(0.81,0.94)$, lower than that of females. In capture-recapture models, mortality and permanent emigration are confounded and it is possible that this difference reflected an asymmetric dispersion between the sexes. The average recapture probability was $0.176 \pm 0.01$ (SE). Unexpectedly, none of the effort-related covariates were retained as predictors of the probability of recapture. This suggests that adult males were always identified, regardless of total number of recording hours or the method used, i.e. data collected to estimate population numbers versus data collected to estimate the number of pups produced. We must add that lower values of probability of capture, between 0.01 and 0.03 , correspond to the months in which only a single male was detected (March 2003, April 2004, September 2005, December 2005, July 2006, August 2006, April 2007, June 2007 and December 2007). We estimated a super-population size of 61.7 (53.4, 70.1; averaged estimate: 60.8, $\mathrm{SE}=4.14$ ) adult males and an estimated range of between 30 and 41 adult males that use the caves in every month sampled (derived parameters of the model fitted; Fig. 2, Table 2). For all 3 groups, SA, AF and $\mathrm{AM}$, we found that estimates for the derived super-population were close to the total number of unique individuals in the photograph catalogue.

\section{DISCUSSION}

Despite the high probability of extinction due to demographic and environmental stochasticity (Lande 1993, Courchamp et al. 1999, Coulson et al. 2001, Berec et al. 2007, Melbourne \& Hastings 2008), small populations maintain the potential for fast growth once conditions improve. The demographic parameters responsible for recovery are often unknown. The present work shows evidence of demographic processes that enhance a population of a long-lived critically endangered species, Monachus monachus, after a crash. The population at Cabo Blanco is now recovering towards the number and age-structure recorded before the occurrence of the demographic crash in 1997, owing to increased survival and breeding propensity in adult females. This confirms the simulated population data noted by Forcada et al. (2002) after a first analysis of population sensitivity.

An important result is that the size of the superpopulation found in our study is very close to the number of individuals identified and currently present and recorded as alive in the photographic catalogue. This suggests that the overall recapture probability is close to unity. In addition, it should be noted that the estimated values of (1) the adult female super-population size, (2) the adult female population that used the caves every year and (3) the number of adult females recorded as being alive in the catalogue are very similar. The match between the estimates and the number of animals that have been seen is particularly evident for females, which suggests that virtually all adult females have been identified and are using the breeding sites on a regular basis. Data from these individuals could be used to directly estimate population-level demographic rates. In contrast, the recapture probability of adult males was found to be lower and independent of the effort invested, which means that males were identified regardless of the effort put into the observations (i.e. whether data were collected to estimate population numbers or the number of pups produced). In this case, the capture probability of adult males can be viewed as the proportion of individuals of this group that uses the caves.

Forcada et al. (1999) provided estimates for the Cabo Blanco population between 1992 and 1997. They found a constant population between 1993 
and 1996, followed by a significant decline in 1997 and 1998. They corrected the estimates of abundance of the distinctive population by a factor defined as the mean proportion of seals with reliable marks in the colony. They calculated this factor for each year of the period of study as the ratio of seals caught to those that were distinctive. The use of this factor introduces uncertainty, because the same value for the numerator can represent very different situations, that is to say that the same non-distinctive seal is captured many times or that there are multiple unrecognizable seals captured. One could assume that the probability of recapture is constant over the years sampled, but, given the results obtained in the present work on identifiable animals, and because sampling is not always performed at the same time of the year, this assumption is unlikely to be met. To avoid this issue, we compared population sizes of distinctive groups of the population. However, a limitation of our study is that we based estimates on individuals that have visited the caves at least once during the 5 yr period of the study. We also note that the values presented by Forcada et al. (1999) are annual population size estimations, as they use different models for each year. Therefore, the 2 population size estimations are not directly comparable. However, the population size estimates derived here seem more conservative than those provided by Forcada et al. (1999). Our results show that the monk seal population at Cabo Blanco is recovering from the significant decline that occurred in 1997. This is because estimates of the number of individuals that used the caves during the period from 2003 to 2007 are larger than the size of the population estimated from the distinctive sector of the population using the data from 1997 to 1998. In addition, censuses in the caves show that the demographic structure we observed is close to that described for this population before the mass mortality event that killed off large numbers of adults (Forcada et al. 1999).

Our observations, together with the estimates from the capture-recapture models, indicate that individual survival after the population crash is high. Adult males had a lower survival level compared to adult females; however, it has to be noted that in this group we found a trap-response effect. This might have led to a slightly lower levels of survival and population size. Also, the annual survival value has been derived by projecting monthly survival, which might also have contributed to the lower value. As expected, sub-adult individuals presented lower survival values than adults (Gaillard et al. 1998), but, in general, survival was high, especially in adult females. High values of survival contribute to high values of individual fitness, since each individual can accumulate a higher probability of reproduction by simply being alive. This is a first step fulfilled by the population for the prompt recovery of its size.

Also, we cannot exclude a role of recruitment processes in avoiding the population extinction after the crash. Indeed, according to Forcada et al. (1999), immature seals were less affected by the mass mortality event than adults. It is possible that these immature individuals recruited into the breeding pool several years after the mass mortality. Given that females at Cabo Blanco can reach sexual maturity at an age of $2.5 \mathrm{yr}$ (Gazo et al. 2000), it is reasonable that the population growth rate (especially the sub-adult-adult stage) was lower soon after the mass mortality event and has later increased following the recruitment of these animals. At present, we do not have sufficient data to fully investigate recruitment processes, but, from our results, it seems that recruitment at Cabo Blanco is low. There was a net annual incorporation of 11 (8.8 to 12.8) individuals into the sub-adult class, but this estimate should be considered under the assumption of stasis within morphological classes, which might overestimate the net incorporation of sub-adults.

The growth in this population is not an isolated phenomenon. Similar population recoveries following catastrophic events have been reported among otrariids (Gerber \& Hilborn 2001). The recovery during the first years appeared to be slower than potentially allowed by the high survival rate of the individuals. This was probably due to the relatively low recruitment rate into the sub-adult class and the absence of immigration. This demographic evidence suggests that the limiting factor for fast population recovery is recruitment. This can be due to (1) low birth rates, (2) low survival rates at young ages (from pups to sub-adult states), or (3) large emigration of juveniles. Despite the claims of earlier studies (Pastor et al. 2004), the birth rate does not seem to be the limiting parameter, since the number of pups born in both caves (data from direct observations, CBD-Habitat unpubl. data) per potential reproductive female (SA and AF estimated in caves) obtained for 2003 to 2007, ranged between 0.46 and 0.62 . González et al. (2002) suggested that the pup survival rate did not vary between pre- and post-mortality events. However, detailed information on juvenile survival and emigration is scarce, and we believe that these factors could be related to the limited rate of SA recruitment detected. 
The recovery might somehow be interpreted as the success of the different measures taken to aid the recovery of the colony in recent years (see González 2006). Probably the most important measure has been the improvement of an effective no-take fisheries zone by the Moroccan authorities, regular surveillance of the coast and marine patrolling, and the seal awareness of fishermen and inhabitants of the area around the main colonies. Improving recruitment and breeding success by increasing the number of safe breeding sites is typically one of the primary measures to enhance the growth of small populations (Gerrodette \& Gilmartin 1990, Gazo et al. 2000, Prugnolle et al. 2003, Dendrinos et al. 2007), but, in our case, more data are necessary to investigate recruitment processes. Further approaches, such as radio or satellite tagging of juveniles or integrated population modelling, might be useful to estimate the missing parameters, i.e. juvenile survival and emigration, to provide a complete understanding of the ecological processes relating to population growth and persistence of the Mediterranean monk seal colony (Coulson et al. 2001, Schaub et al. 2007, Tavecchia et al. 2009).

Acknowledgements. The authors thank all the personnel of the CBD-Habitat monk seal conservation project in Cabo Blanco, specially Hamdi M'Barek and Moulaye Ould Haye, who made this work possible with their participation, support and dedication to the conservation of this monk seal colony throughout the study period. We are also grateful to Antonio Araujo, Mohamed Saleh Menna and Mohamadou Youssouf Diagana from the Banc d'Arguin National Park; Azza Mint Jiddou from the IMROP; M'hamed Idrissi, Amina Moumni, Bensbai Jilali and Ismail Azaguagh from the INRH; Marco Barbieri from the CMS/UNEP; Miguel Aymerich, Borja Heredia and José Jiménez from the DG Medio Natural; Francisco Cantos from the OAPN; and Beatriz Bastos, Soledad Centenera and Jose Manuel Cornejo from Grupo TRAGSA for their support in different stages of the work. This work was developed under the framework of the 'Action Plan for the recovery of the Mediterranean monk seal in the eastern Atlantic' and was funded by The Ministry of Environment of Spain, the MAVA Foundation, Fundación Biodiversidad and Agencia Española de Cooperación Internacional para el Desarrollo.

\section{LITERATURE CITED}

Berec L, Angulo E, Courchamp F (2007) Multiple Allee effects and population management. Trends Ecol Evol 22:185-191

Burnham KP, Anderson DR (2000) Model selection and multimodel inference: a practical information-theoretical approach. Springer, New York, NY

Catchpole EA, Morgan BJT, Coulson TN, Freeman SN, Albon SD (2000) Factors influencing Soay sheep survival. J R Stat Soc Ser C Appl Stat 49:453-472
Choquet R, Lebreton JD, Gimenez O, Reboulet AM, Pradel R (2009) U-CARE: utilities for performing goodness of fit tests and manipulating capture-recapture data. Ecography 32:1071-1074

Cooch EG, White GC (2007) MARK: a gentle introduction. Available at: www.phidot.org/software/mark/docs/book (accessed February 2008)

Coulson T, Mace GM, Hudson E, Possingham H (2001) The use and abuse of population viability analysis. Trends Ecol Evol 16:219-221

Courchamp F, Clutton-Brock T, Grenfell B (1999) Inverse density dependence and the allee effect. Trends Ecol Evol 14:405-410

> Dendrinos P, Karamanlidis AA, Kotomatas S, Legakis A, Tounta E, Matthiopoulos J (2007) Pupping habitat use in the Mediterranean monk seal: a long-term study. Mar Mamm Sci 23:615-628

Forcada J, Aguilar A (2000) Use of photographic identification in capture-recapture studies of Mediterranean monk seals. Mar Mamm Sci 16:767-793

Forcada J, Hammond PS, Aguilar A (1999) Status of the Mediterranean monk seal Monachus monachus in the western Sahara and the implications of a mass mortality event. Mar Ecol Prog Ser 188:249-261

Forcada J, Mozetich I, Miller P (2002) Risk assessment and population modeling. In: González LM, Heredia B, Araujo A, Worms J, Miller PS, Seal U (eds) Population and habitat viability assessment for the Mediterranean monk seal (Monachus monachus) in the eastern Atlantic. Workshop report. IUCN/SSC Conservation Breeding Specialist Group, Apple Valley, MN, p 1-126

Gaillard JM, Festa-Bianchet M, Yoccoz NG (1998) Population dynamics of large herbivores: variable recruitment with constant adult survival. Trends Ecol Evol 13:58-63

> Gazo M, Aparicio F, Cedenilla MA, Layna JF, González LM (2000) Pup survival in the Mediterranean monk seal (Monachus monachus) colony of the Cabo Blanco peninsula (Mauritania). Mar Mamm Sci 16:158-168

Gerber LH, Hilborn R (2001) Catastrophic events and recovery from low densities in populations of otariids: implications for risk of extinction. Mammal Rev 31:131-150

> Gerrodette T, Gilmartin WG (1990) Demographic consequences of changed pupping and hauling sites of the Hawaiian monk seal. Conserv Biol 4:423-430

González LM (ed) (2006) The action plan for the recovery of the Mediterranean monk seal in the eastern Atlantic. O.A. Parques Nacionales, Ministerio de Medio Ambiente, Madrid

González LM, Aguilar A, Lopez-Jurado LF, Grau E (1997) Status and distribution of the Mediterranean monk seal Monachus monachus on the 'Cabo Blanco' peninsula (western Sahara-Mauritania) in 1993-1994. Biol Conserv 80:225-233

González LM, Cedenilla M, Aparicio F, Fernandez de Larrinoa P (2002) Changes in the breeding variables of the Mediterranean monk seal (Monachus monachus) colony of Cabo Blanco after a mass-mortality episode. Mammalia 66:173-182

- Good TP, Davies J, Burke BJ, Ruckelshaus MH (2008) Incorporating catastrophic risk assessments into setting conservation goals for threatened Pacific salmon. Ecol Appl 18:246-257

Harwood J (1998) What killed the monk seals? Nature 393: $17-18$

IUCN (International Union for Conservation of Nature) 
(2010) IUCN red list of threatened species, Version 2010.3. Available at: www.iucnredlist.org (accessed 18 October 2010)

Lande R (1993) Risk of population extinction from demographic and environmental stochasticity and random catastrophes. Am Nat 142:911-927

Mangel M, Tier C (1994) Four facts every conservation biologist should know about persistence. Ecology 75 : 607-614

Martínez-Abraín A, Tavecchia G, Regan HM, Jiménez J, Surroca M, Oro D (2012) Effects of wind farms and food scarcity on a large scavenging bird species following an epidemic of bovine spongiform encephalopathy. J Appl Ecol 49:109-117

Melbourne BA, Hastings A (2008) Extinction risk depends strongly on factors contributing to stochasticity. Nature 454:100-103

Oro D, Ruxton GD (2001) The formation and growth of seabird colonies: Audouin's gull as a case study. J Anim Ecol 70:527-535

Pastor T, Garza JC, Allen P, Amos B, Aguilar A (2004) Low genetic variability in the highly endangered Mediterranean monk seal. J Hered 95:291-300

Prugnolle F, Pilard P, Brun L, Tavecchia G (2003) First-year and adult survival of the endangered lesser kestrel Falco naumanni in southern France. Bird Study 50:68-72

Reyero M, Cacho E, Martínez A, Vázquez J, Marina A, Fraga S, Franco JM (1999) Evidence of saxitoxin derivatives as causative agents in the 1997 mass mortality of monk seals in the Cape Blanc peninsula. Nat Toxins 7 : 311-315

Samaranch R, González LM (2000) Changes in morphology with age in Mediterranean monk seals (Monachus monachus). Mar Mamm Sci 16:141-157

Schaub M, Gimenez O, Sierro A, Arlettaz R (2007) Use of integrated modeling to enhance estimates of population dynamics obtained from limited data. Conserv Biol 21: 945-955

Schwarz CJ, Arnason AN (1996) A general methodology for the analysis of capture-recapture experiments in open populations. Biometrics 52:860-873

- Tavecchia G, Besbeas P, Coulson T, Morgan BJT, CluttonBrock TH (2009) Estimating population size and hidden demographic parameters with state-space modeling. Am Nat 173:722-733

White GC, Burnham KP (1999) Program MARK: survival rate estimation from both live and dead encounters. Bird Study 46(Suppl):120-139

APPENDIX 1. Table A1. Monachus monachus. Modelling population size of adult and sub-adult monk seals at Cabo Blanco. Data were analysed using the POPAN parameterization. Models are ordered by the $\triangle$ AICc value-the difference between each AICc value and the minimum value-and retained models are in bold. Parameters - \{phi\}: probability of survival between 2 consecutive sampling occasions; $\{\mathrm{p}\}$ : probability of capture at each occasion; \{pent\}: probability that an animal enters the population between 2 consecutive occasions and survives to the next sampling occasion; $\{\mathrm{N}\}$ : super-population size. Notation-(month): variables vary between months; $(\mathrm{h})$ : variables vary between morphological classes; (year): variables vary from one year to the next; (.): variables are constant; $(\mathrm{H})$ : a covariate calculated as the number of hours of recording every month; (P): a factorial variable describing the presence or absence of pups in the cave; Np: number of parameters in the model. ' $x$ ' denotes the statistical interaction between the effects; ' + ' indicates an additive relationship

\begin{tabular}{|c|c|c|c|c|c|}
\hline Model & $\triangle \mathrm{AICC}$ & $\mathrm{Np}$ & Model & $\triangle \mathrm{AICc}$ & $\mathrm{Np}$ \\
\hline Sub-adult and adult females & & & Adult males & & \\
\hline$\{$ phi(.) $\mathrm{p}(.) \operatorname{pent}(.) \mathrm{N}(\mathrm{h})\}$ & 29.5 & 5 & $\{$ phi(month) p(.) pent(month) $\mathrm{N}\}$ & 252.5 & 63 \\
\hline$\{$ phi(.) p $($ year $\times$ h) pent $($ year $\times$ h) $\mathrm{N}(\mathrm{h})\}$ & 24.3 & 16 & $\{$ phi(month) $\mathrm{p}$ (month) pent(month) $\mathrm{N}\}$ & 199.2 & 125 \\
\hline$\{$ phi(h) $p($.$) pent(year) N(h)\}$ & 22.4 & 8 & $\{$ phi(.) $\mathrm{p}(\mathrm{H})$ pent(year) $\mathrm{N}\}$ & 169.4 & 7 \\
\hline$\{$ phi $($ year $\times h)$ p $($ year $\times h)$ pent $($ year $\times h) N(h)\}$ & ) 18.0 & 20 & $\{$ phi(.) p(.) pent(year) $\mathrm{N}\}$ & 167.4 & 6 \\
\hline$\{$ phi $(\mathrm{h})$ p $($ year $\times \mathrm{h})$ pent $($ year $\times \mathrm{h}) \mathrm{N}(\mathrm{h})\}$ & 12.9 & 16 & $\{$ phi(.) p(year) pent(year) $\mathrm{N}\}$ & 153.6 & 10 \\
\hline$\{$ phi $($ year $\times \mathrm{h}) \mathrm{p}($ year $+\mathrm{h})$ pent $($ year $\times \mathrm{h}) \mathrm{N}(\mathrm{h})\}$ & 12.4 & 17 & $\{$ phi(.) $\mathrm{p}(\mathrm{P})$ pent(year) $\mathrm{N}\}$ & 149,8 & 7 \\
\hline$\{$ phi(.) $\mathrm{p}(\mathrm{h})$ pent $($ year $\times \mathrm{h}) \mathrm{N}(\mathrm{h})\}$ & 12.3 & 10 & $\{$ phi(.) $\mathrm{p}(\mathrm{H} \times \mathrm{P})$ pent $($ year $) \mathrm{N}\}$ & 83.5 & 9 \\
\hline$\{$ phi(.) p(.) pent(h) $\mathrm{N}(\mathrm{h})\}$ & 11.6 & 6 & $\{$ phi(year) p(month) pent(year) $\mathrm{N}\}$ & 6.0 & 67 \\
\hline$\{$ phi $($ year $\times$ h)p $($ year $\times h)$ pent $(h) N(h)\}$ & 11.5 & 16 & $\{$ phi(.) p(month) pent(.) N\} & 4.1 & 61 \\
\hline$\{$ phi $($ year $\times \mathrm{h}) \mathrm{p}(\mathrm{h})$ pent $($ year $\times \mathrm{h}) \mathrm{N}(\mathrm{h})\}$ & 9.5 & 15 & $\{$ phi(.) p(month) pent(t) $\mathrm{N}\}$ & 3.2 & 69 \\
\hline$\{$ phi $($ year $\times$ h) $\mathrm{p}($.$) pent ($ year $\times \mathrm{h}) \mathrm{N}(\mathrm{h})\}$ & 8.0 & 14 & $\{$ phi(.) p(month) pent(year) $N\}$ & - & 63 \\
\hline$\{$ phi(h) $\mathrm{p}(\mathrm{h})$ pent $($ year $\times \mathrm{h}) \mathrm{N}(\mathrm{h})\}$ & 4.5 & 11 & & & \\
\hline$\{$ phi(h) $\mathrm{p}($.$) pent ($ year $\times \mathrm{h}) \mathrm{N}(\mathrm{h})\}$ & 3.0 & 10 & & & \\
\hline$\{$ phi(h) p(.) pent(h) N(h)\} & - & 7 & & & \\
\hline
\end{tabular}

